\title{
Nanospheres to nanosheets: unfolding the morphological influence of microporous organic polymers on micropollutants removal
}

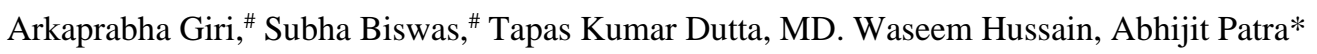 \\ Department of Chemistry, Indian Institute of Science Education and Research Bhopal, Bhopal Bypass Road, Bhauri, Bhopal 462066, Madhya \\ Pradesh, India. E-mail: abhijit@iiserb.ac.in.
}

\#These authors contributed equally

\begin{abstract}
Nanoporous organic polymers with distinct morphologies are of immense interest for a broad spectrum of applications ranging from catalysis to molecular separation, energy storage, and energy conversion. However, developing facile and versatile methodologies to obtain well-orchestrated morphologies along with high specific surface area pertinent to a specific application is still a formidable challenge. The design of the task-specific networks can be benefitted through further analysis of subtle variations in the polymerization conditions. Herein, we have critically examined the fabrication of triptycene-based hypercrosslinked polymers (HCPs), exhibiting contrasting morphologies developed through three distinct polymerization routes. Astonishingly, a remarkable variation of nanostructured morphology of irregular aggregates, nanospheres, and nanosheets was noticeable in the resultant network polymers through FriedelCrafts crosslinking using dimethoxymethane as an external crosslinker, Scholl coupling, and solvent knitting using dichloromethane as an external crosslinker and solvent, respectively. The dramatic role of reaction temperature, catalysts, and solvents driving the formation of specific nanostructured HCPs was elucidated. Mechanistic investigations coupled with spectroscopic and microscopic studies revealed that the 2D-nanosheets of highly porous solvent-knitted HCP (SKTP, $\mathrm{S}_{\mathrm{BET}}: 2385 \mathrm{~m}^{2} \mathrm{~g}^{-1}$ ) evolved through the hierarchical self-assembly of rigid nanospheres into nanoribbons followed by the formation of nanosheets. We further demonstrated a structure-activity correlation of the pristine as well as post-synthetically sulfonated HCPs for the removal of a gamut of organic micropollutants from water. Solvent knitted triptycene polymer (SKTP) and its sulfonated derivative (SKTPS, $\mathrm{S}_{\mathrm{BET}}: 1444 \mathrm{~m}^{2} \mathrm{~g}^{-1}$ ) owing to high specific surface areas, excellent dispersity in water, and better accessibility of analytes through 2D-sheet like morphology exhibited ultrafast sequestration ( $30 \mathrm{~s}$ to $5 \mathrm{~min}$ ) of an extensive array of persistent organic micropollutants, including ionic dyes, plastic components, steroids, antibiotic drugs, and herbicides with excellent recyclability. The current study holds the promise that a delicate control over the morphologies of nanoporous polymers by tuning the fabrication conditions paves the way for the development of advanced porous materials for environmental remediation.
\end{abstract}

\section{Introduction}

Morphology and textural features of materials are essential parameters to influence their physicochemical properties, such as porosity, adsorption, diffusion kinetics, accessibility of the active sites for catalysis, and optoelectronic properties. ${ }^{1,2}$ Porous materials with well-organized nanomorphologies (e.g., hollow sphere, microtube, nanosheet) are of immense interest in various applications ranging from molecular separation, catalysis, energy storage to drug delivery. ${ }^{2}$ All-organic nanoporous polymers having low skeleton density, excellent structuralfunctional diversity, along with high porosity have emerged as the holy grail in the domain of porous materials. ${ }^{3}$ Despite their tunable functional properties, the drastic fabrication conditions, such as the use of noble-metal catalysts, inert atmosphere, and design of sophisticated monomers, significantly retard the scalability and translational scope of these materials from the laboratory to the marketplace. In this context, hypercrosslinked polymers (HCPs), originally designated as Davankov resins, ${ }^{4}$ are found to be highly applicable due to the use of readily available aromatic building units, cheap and scalable fabrication techniques (Lewis acid-mediated synthesis), high porosity, and excellent hydrothermal stability. However, it is extremely challenging to control their nanomorphology owing to the kinetically driven unrestricted polymerization conditions. ${ }^{5}$
In previous years, considerable efforts have been made to attain specific control over the morphology, such as hard/soft templating techniques, ${ }^{6}$ and template-free synthesis. ${ }^{7}$ However, a versatile, cost-effective, scalable, template-free route is highly desirable to precisely control the nanomorphology along with the definite porosity of the HCPs. Tan and coworkers made a pioneering contribution to the development of HCPs using halogenated solvents as external crosslinkers to achieve layered sheet-like morphology, known as the 'solvent knitting' method. ${ }^{8}$ Dai and coworkers crosslinked the diblock copolymer micelles of poly(ethylene oxide)- $b$-polystyrene through Friedel-Crafts reaction to obtain hollow sphere-like morphology. ${ }^{9}$ Jiang and coworkers developed a range of HCPs using dimethoxy methane (DMM) as an external crosslinker and $\mathrm{FeCl}_{3}$ as a catalyst to obtain one-dimensional nanotubes..$^{10}$ Amid all these studies, the evolution of nanomorphologies of microporous HCPs and their impact on sorption properties have rarely been addressed. Herein, we investigated the influence of synthetic methodologies for tailoring the morphology of triptycene-based HCPs from irregular aggregates (FCTP) to nanospheres (SCTP) to nanosheets (SKTP), respectively obtained through Friedel-Crafts reaction (using external crosslinker dimethoxymethane, DMM), Scholl coupling, and solvent-knitting method employing dichloromethane (DCM) as an external crosslinker and solvent (Fig. 1). The sulphonated polymers obtained through postsynthetic modification were found to retain a similar morphology 


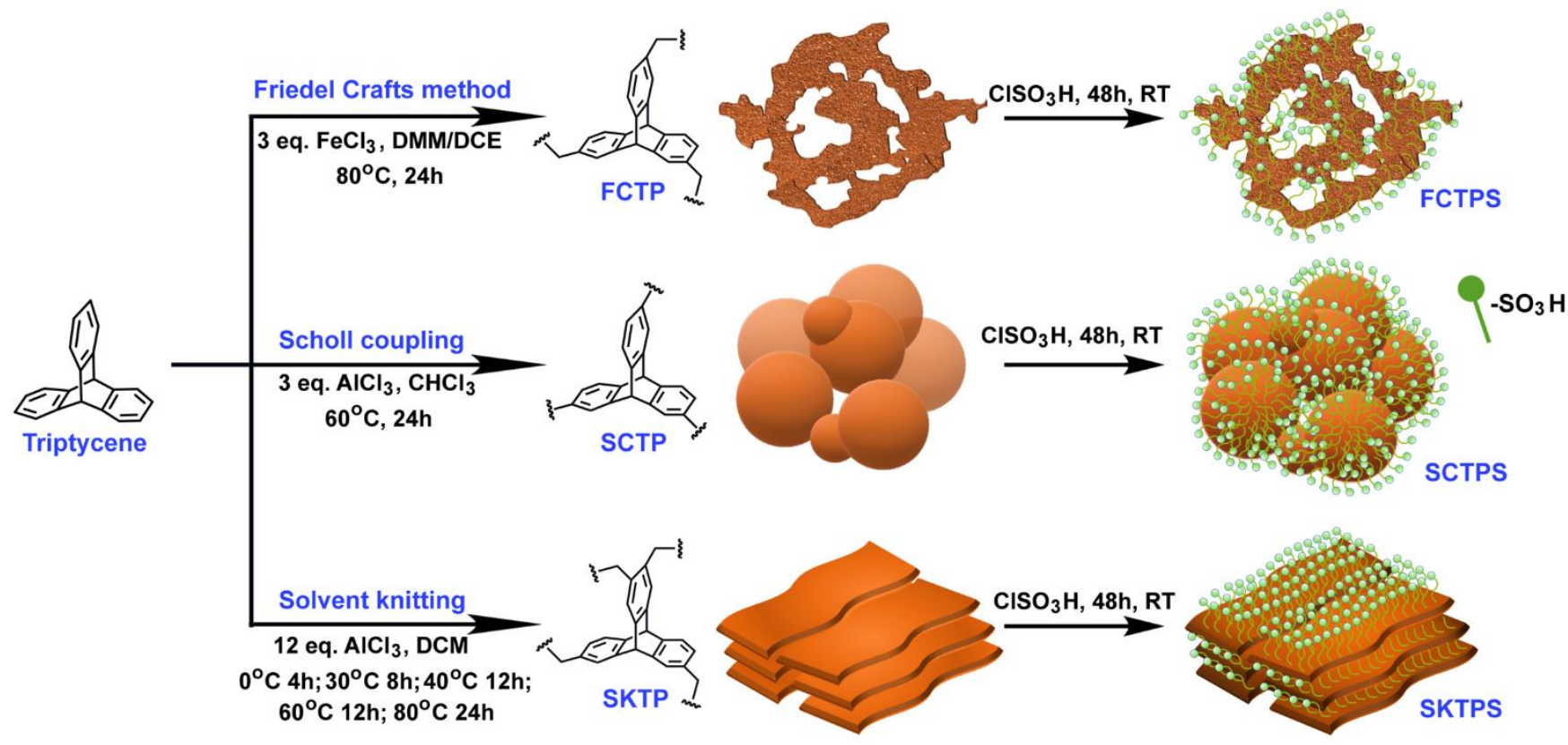

Fig. 1. Synthetic schemes of triptycene-based hypercrosslinked polymers (HCPs). Irregular, rigid sphere-like, and layered sheet-like morphology obtained through Friedel-Crafts reaction (FCTP), Scholl coupling reaction (SCTP), and solvent knitting method (SKTP), respectively. Post-synthetic sulfonation of HCPs resulted in FCTPS, SCTPS, and SKTPS retaining the morphological features of respective pristine HCPs.

as observed in pristine HCPs. Through mechanistic investigations coupled with electron and atomic force microscopy, we rationalize for the first time that the evolution of 2D-nanosheets of solvent knitting polymer is the consequence of hierarchical self-assembly of nanospheres and nanoribbons formed at the various stages of the crosslinking.

In order to interpret a structure-activity correlation of the highly porous HCPs (S BET: $1247 \mathrm{~m}^{2} \mathrm{~g}^{-1}$ to $2385 \mathrm{~m}^{2} \mathrm{~g}^{-1}$ ) with contrasting morphology, we employed them for the removal of organic micropollutants from water. We observed that solventknitted HCPs having high specific surface area, excellent dispersity, and, more importantly, better pore accessibility due to the 2D-sheet-like morphology showed faster adsorption kinetics for cationic, anionic, and neutral micropollutants than the networks obtained through Scholl coupling and Friedel-Crafts crosslinking using DMM. Furthermore, the sulfonated counterpart of solvent knitted HCP (SKTPS) exhibited a remarkable removal efficiency for a gamut of persistent organic micropollutants, including antibiotics, endocrine disruptors, steroid-based drugs, dyes, plastic precursors, herbicides within $30 \mathrm{~s}$ to $5 \mathrm{~min}$ with excellent recyclability. Moreover, SKTPS exhibited an excellent adsorption performance for a wide range of $\mathrm{pH}$ (3 to 9). The present work thereby provides critical insights into the fine tuning of the morphology of the HCPs as well as the structure-activity correlation based on the rapid sequestration of organic micropollutants from water, promising for further development of advanced task-specific materials for environmental remediation.

\section{Results and Discussion}

We employed conventional Friedel-Crafts reaction, Scholl coupling, and solvent knitting method for the fabrication of HCPs (Fig. 1). Triptycene was chosen as the building block because of its fascinating paddle wheel-like topology and 'internal free volume' $\left(31 \AA^{3}\right)$, resulting in inefficient packing of the polymer chains. ${ }^{11}$ Triptycene monomers were crosslinked through methylene linkages in the presence of dimethoxymethane as an external crosslinker and dichloroethane (DCE) as a solvent in the Friedel-Crafts alkylation reaction catalysed by $\mathrm{FeCl}_{3}$ ( 3 eq.). After $24 \mathrm{~h}$ of stirring at $80^{\circ} \mathrm{C}$, the reaction yielded the $\mathrm{HCP}$ with irregular aggregated morphology, FCTP. On the other hand, Scholl coupling of triptycene was catalysed by $\mathrm{AlCl}_{3}$ (3 eq.) in chloroform at $60^{\circ} \mathrm{C}$ for $24 \mathrm{~h}$. The polymerization proceeded through a radical mechanism where triptycene monomers were connected by $\mathrm{C}-\mathrm{C}$ coupling leading to rigid spherical particles of SCTP. In the solvent-knitting reaction, the dichloromethane (DCM) was employed as a solvent as well as a crosslinker to knit triptycene molecules in the presence of a higher amount of $\mathrm{AlCl}_{3}$ (12 eq.). The reaction temperature was gradually varied from $0^{\circ} \mathrm{C}(4 \mathrm{~h}), 30^{\circ} \mathrm{C}(8 \mathrm{~h})$, $40^{\circ} \mathrm{C}(12 \mathrm{~h}), 60^{\circ} \mathrm{C}(12 \mathrm{~h})$ to $80^{\circ} \mathrm{C}(24 \mathrm{~h})$ and resulted in SKTP exhibiting stacked sheet-like morphology. All the polymerization processes score in the range of 71-75 on the EcoScale parameter of $0-100$, indicating adequate green synthetic and sustainable protocols in view of the safety, economic, and ecological perspectives. ${ }^{12}$ The post-synthetic sulfonation $\left(-\mathrm{SO}_{3} \mathrm{H}\right)$ was carried out through the addition of chlorosulfonic acid in the dispersion of respective HCPs in DCM and stirring for $48 \mathrm{~h}$ at room temperature.

HCPs with diverse morphology were characterized by several spectroscopic and microscopic techniques. The solidstate cross-polarization magic angle spinning ${ }^{13} \mathrm{C}$ nuclear magnetic resonance (CP/MAS ${ }^{13} \mathrm{C}$ SSNMR) spectroscopy revealed the peaks corresponding to unsubstituted and substituted aromatic carbons of HCPs in the range of 120-135 and $145 \mathrm{ppm}$, respectively (Fig. 2a). The triptycene building units in FCTP, SCTP, and SKTP were substantiated by the peak at $54 \mathrm{ppm}$ attributed to the $\mathrm{sp}^{3}$ hybridized paddle-wheel or bridgehead carbon. The peaks at 30-37 ppm indicate the polymerization of triptycene through methylene bridges 

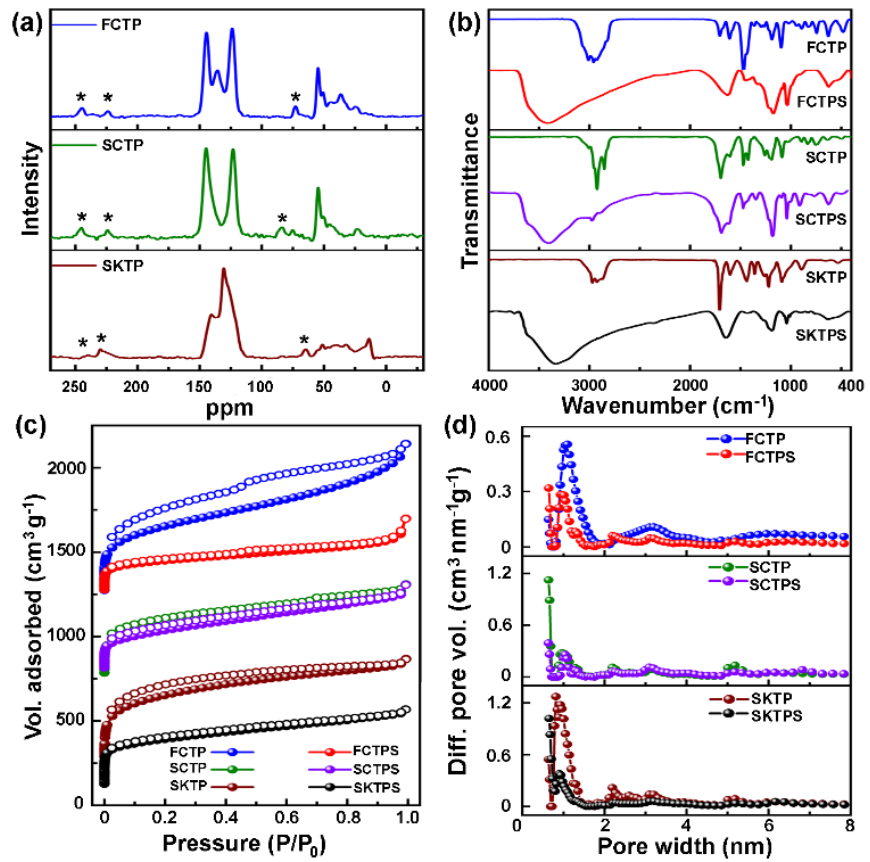

Fig. 2 (a) Solid-state ${ }^{13} \mathrm{C}$-(CP/MAS) NMR spectra of pristine HCPs: FCTP, SCTP, and SKTP (*indicates the spinning sidebands). (b) FTIR spectra, (c) $\mathrm{N}_{2}$ sorption isotherms at $77 \mathrm{~K}$, and (d) pore size distribution based on quenched solid density functional theory (QSDFT) method of the pristine HCPs (FCTP, SCTP, and SKTP) and sulfonated HCPs (FCTPS, SCTPS, SKTPS), respectively.

resulting in FCTP and SKTP. The Fourier transform infrared (FTIR) spectroscopic analysis of pristine HCPs showed the aromatic $\mathrm{C}-\mathrm{H}$ stretching of triptycene around $3000 \mathrm{~cm}^{-1}$ (Fig. 2b). Peaks at $2855 \mathrm{~cm}^{-1}$ and $2930 \mathrm{~cm}^{-1}$ were attributed to the symmetric and asymmetric stretching of aliphatic $\mathrm{C}-\mathrm{H}$, respectively, due to the $\mathrm{sp}^{3}$ carbon of triptycene as well as the alkyl crosslinkers. The peaks found in the region of 1500-1700 $\mathrm{cm}^{-1}$ were designated to the aromatic $\mathrm{C}=\mathrm{C}$ stretching of triptycene moieties. After sulfonation of HCPs, the peaks that emerged at $1300 \mathrm{~cm}^{-1}$ and $1160 \mathrm{~cm}^{-1}$ were attributed to the $-\mathrm{S}=\mathrm{O}$ stretching (asymmetric and symmetric stretching vibrations of $\mathrm{SO}_{3} \mathrm{H}$ group, Fig. 2b). The broadband around $3400 \mathrm{~cm}^{-1}$ ascribed to the $-\mathrm{OH}$ stretching of the $-\mathrm{SO}_{3} \mathrm{H}$ group ascertaining the successful post-synthetic sulfonation (Fig. 2b). Furthermore, the X-ray photoelectron spectroscopic (XPS) analysis of FCTPS and SKTPS suggested that the peaks centered at 169.7 and $168.1 \mathrm{eV}$ were due to the $\mathrm{S} 2 \mathrm{p}_{1 / 2}$ and $\mathrm{S} 2 \mathrm{p}_{3 / 2}$ of $-\mathrm{SO}_{3} \mathrm{H}$ group, respectively. Whereas, the peaks at 167.6 and $165.1 \mathrm{eV}$ are ascribed for the $\mathrm{S} 2 \mathrm{p}_{1 / 2}$ and $\mathrm{S} 2 \mathrm{p}_{3 / 2}$ of $-\mathrm{SO}_{3}{ }^{-}$group. On the other hand, peaks for $\mathrm{SO}_{3} \mathrm{H}$ and $-\mathrm{SO}_{3}{ }^{-}$in SCTPS appeared slightly at lower binding energy, $169.2,168.0 \mathrm{eV}$, and 165.2 and $164.0 \mathrm{eV}$, respectively. This might be due to the $\pi$-electron delocalization between successive triptycene units in SCTPS compared to the methylene-bridged FCTPS and SKTPS. ${ }^{13,14}$

The broad PXRD patterns denote the amorphous nature of HCPs occurring due to the kinetically driven polymerization. ${ }^{5}$ Thermogravimetric analysis (TGA) revealed high thermal stability of HCPs; the pristine polymers were stable up to $320^{\circ} \mathrm{C}$, and sulfonated polymers were found to be stable up to $220^{\circ} \mathrm{C}$. The weight loss of $\sim 5-10 \%$ at $100^{\circ} \mathrm{C}$ in sulfonated $\mathrm{HCPs}$ indicated the removal of the moisture trapped due to the $-\mathrm{SO}_{3} \mathrm{H}$ functionalization. ${ }^{14}$ Zeta potential measurements suggested surface-excess negative charge for HCPs and the further enhancement of the same in the sulfonated HCPs due to the deprotonation of sulfonic acid groups.

The specific BET surface areas of HCPs were estimated through nitrogen sorption analysis at $77 \mathrm{~K}$. The type-IV isotherm of FCTP with a steep nitrogen uptake at a very low relative pressure $\left(\mathrm{p} / \mathrm{p}_{0}<0.05\right)$ followed by a large $\mathrm{H} 4$ type hysteresis loop suggested the presence of both micro and mesopores. ${ }^{15}$ On the other hand, SCTP and SKTP showed Type-I isotherms with a steep nitrogen uptake at $\mathrm{p} / \mathrm{p}_{0}<0.05$, indicating microporous structure. $^{15}$ The Brunauer-Emmett-Teller (BET) specific surface areas of FCTP, SCTP, and SKTP were found to be 1626 , 1247 , and $2385 \mathrm{~m}^{2} \mathrm{~g}^{-1}$, respectively (Fig. 2c). However, the postsynthetic sulfonation-induced pore-blocking led to a reduction in surface area of FCTPS: $916 \mathrm{~m}^{2} \mathrm{~g}^{-1}$, SCTPS: $1122 \mathrm{~m}^{2} \mathrm{~g}^{-1}$, and SKTPS: $1444 \mathrm{~m}^{2} \mathrm{~g}^{-1}$ having Type-I isotherms. ${ }^{13 a}$ The pore size distribution (PSD) of all the HCPs was estimated through quenched solid density functional theory (QSDFT, Fig. 2d) method explicitly considering the effects of heterogeneity and surface roughness of the pore structure. ${ }^{16}$ The PSD profile of FCTP showed the centering of micropores at 0.64 and $1 \mathrm{~nm}$ along with the mesopores distributed from 2 to $8 \mathrm{~nm}$ (Fig. 2d). On the contrary, the narrow bimodal PSD around 0.64 and 0.89 nm was observed for SKTP (Fig. 2d). SCTP exhibited highly precise unimodal PSD at the ultramicroporous domain at 0.64 $\mathrm{nm}$ (Fig. 2d). We inferred that the pores at $0.64 \mathrm{~nm}$ might be due to the inefficient packing of two triptycene cores. Whereas helic[6]arene types of pore structure might be responsible for the pore diameter of $\sim 0.9 \mathrm{~nm}$ observed in SKTP.${ }^{17}$ Further, the large pore volumes (FCTP: $1.46 \mathrm{~cm}^{3} \mathrm{~g}^{-1}$; SCTP: $0.94 \mathrm{~cm}^{3} \mathrm{~g}^{-1}$; SKTP: $1.34 \mathrm{~cm}^{3} \mathrm{~g}^{-1}$ at $0.99 \mathrm{p} / \mathrm{p}_{0}$ ) prompted us to explore the sorption property of HCPs.

\section{Morphological evolution of HCPs}

HCPs developed through three different fabrication routes exhibited distinct morphologies. The rapid reaction between external crosslinker dimethoxymethane and triptycene in the presence of Lewis acid catalyst $\left(\mathrm{FeCl}_{3}\right)$ and dichloroethane (DCE) as solvent resulted in irregular aggregated morphology of FCTP obtained through the Friedel-Crafts alkylation (Fig. 3a, 3d). Such irregular morphology resulted in hierarchical PSD encompassing both micro and mesopores, as revealed from the analysis of BET isotherms (Fig. 2c, 2d). Whereas, the morphological control was achieved in the Scholl coupling and the solvent knitting methods providing rigid spherical particles of SCTP (Fig. 3b, 3e, 3g) and stacked nanosheets of SKTP (Fig. $3 \mathrm{c}$, 3f, 3h), respectively. The high-resolution transmission electron microscopy (HRTEM) and atomic force microscopy (AFM) images of HCP samples fabricated through ultrasonication in methanol revealed that the diameters of rigid spherical particles of SCTP were in the range of $\sim 100-500 \mathrm{~nm}$ (Fig. 3e, 3g). The average thickness of SKTP nanosheets obtained through ultrasonic-assisted solvent exfoliation was found to be $\sim 40 \mathrm{~nm}$, as revealed from the AFM analysis (Fig. $3 h)$. 

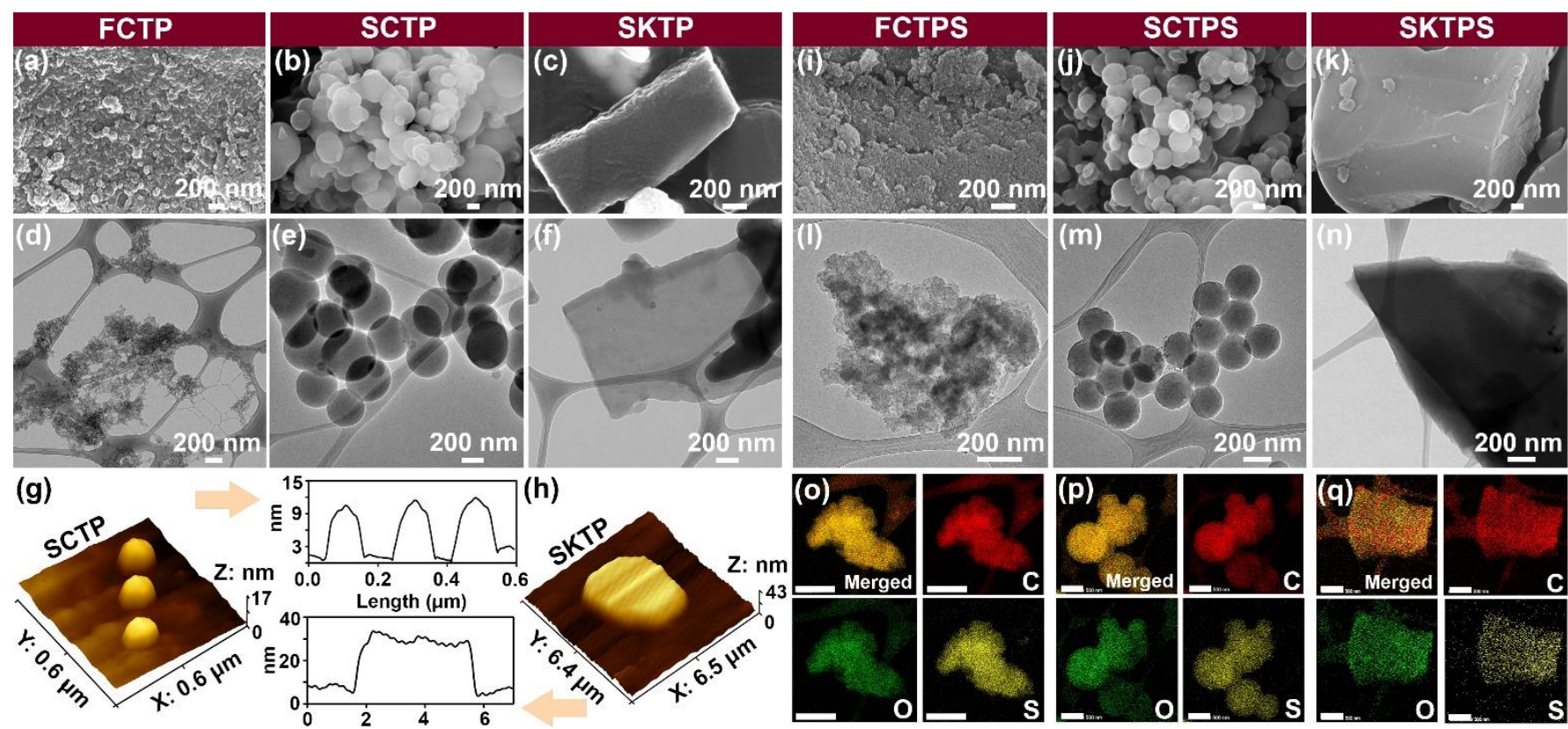

(h)

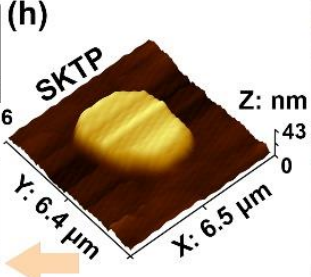

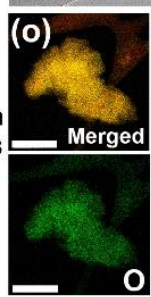
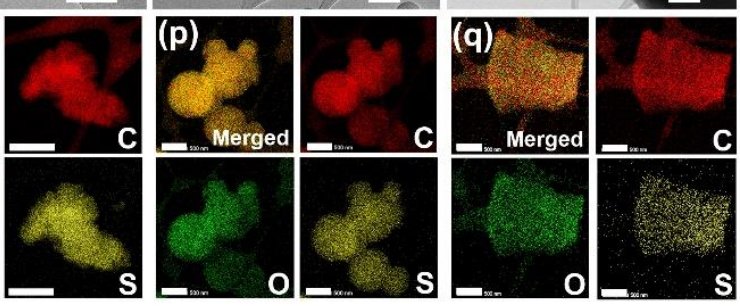

Fig. 3 Field emission scanning electron microscopy (FESEM) images of (a) FCTP, (b) SCTP, and (c) SKTP. Corresponding high-resolution transmission electron microscopy (HRTEM) images of (d) FCTP, (e) SCTP, and (f) SKTP indicating irregular, rigid sphere and sheet-like morphologies, respectively. Atomic force microscopy (AFM) images of (g) SCTP, (h) SKTP, and the respective height profiles shown at the middle panel suggesting layered morphology for SKTP. FESEM images of sulfonated HCPs (i) FCTPS, (j) SCTPS, (k) SKTPS; and corresponding HRTEM images of (l) FCTPS, (m) SCTPS, (n) SKTPS suggesting similar morphologies as that of respective pristine HCPs. High-angle annular dark-field (HAADF) TEM imaging of (o) FCTPS, (p) SCTPS, and (q) SKTPS revealing homogeneous distribution of carbon (red), oxygen (green), and sulphur (yellow); scale bar: 500 nm.

The morphology of HCPs after sulfonation was found to be consistent with that of the pristine one (Fig. 3i-3n). The highangle annular dark-field (HAADF) TEM images of sulfonated polymers revealed the homogeneous distribution of $\mathrm{C}, \mathrm{O}$, and $\mathrm{S}$ confirming the successful grafting of sulfonic acid groups (Fig. 3o-3q). Additionally, the weight percentages of sulfur in FCTPS, SCTPS, and SKTPS were found to be 9.3, 5.3, and 3.7 from the elemental analysis. The less sulfur content of SCTPS compared to FCTPS might be due to the sulfonation of the outer surface of the rigid spheres. Whereas, a higher degree of substitution in triptycence monomers due to the extensive crosslinking in solvent knitting polymerization led to the decrease of available sites for sulfonation.

The irregular morphology of the networks through the Friedel-Crafts reaction is attributed to the rapid condensation of triptycene monomers in the presence of highly reactive crosslinker dimethoxymethane. ${ }^{18}$ Recent studies also indicated that the chlorinated solvent, dichloroethane used in the FriedelCrafts polymerization also took part in the reaction in the presence of a Lewis acid. ${ }^{8}$ Thus, reactions of triptycene with DMM and DCE having different reactivity in the presence of $\mathrm{FeCl}_{3}$ led to uncontrolled network formation resulting irregular morphology. The monomeric units are linked in the Scholl coupling without having any significant involvement of solvent molecules in the reaction. In contrast, the less reactive crosslinker dichloromethane (DCM) decelerated the crosslinking process in the solvent knitting method. ${ }^{18}$ As a consequence, the polymerization proceeds in a more controlled way allowing efficient packing and self-assembly of polymer chains grown through a smooth knitting process of the building units. ${ }^{18}$

We carried out the time-dependent morphology analysis using HRTEM imaging to elucidate the morphological evolution of SKTP thin-sheets (Fig. 4). We observed the formation of nanospheres at the initial stage of the reaction (during $4 \mathrm{~h}$ of reaction at $0^{\circ} \mathrm{C}$, Fig. 4a). The nanospheres were fused to form nanoribbons when the reaction was extended further $\left(4 \mathrm{~h}\right.$ at $0^{\circ} \mathrm{C}$ followed by $8 \mathrm{~h}$ at $30^{\circ} \mathrm{C}$, Fig. 4b). Finally, the nanoribbons were found to assemble in a lateral manner forming 2D-nanosheets with the gradual increase in the reaction temperature with time (Fig. 4c, 4d, 4e). The morphological evolution of SKTP from nanosphere to nanoribbon to nanosheet was corroborated with the gradual increase in the specific BET surface area. The surface area of $590 \mathrm{~m}^{2} \mathrm{~g}^{-1}$ (reaction at $0^{\circ} \mathrm{C}$ for $4 \mathrm{~h}$ followed by $30^{\circ} \mathrm{C}$ for $8 \mathrm{~h}$, Fig. 4a) was increased to $1234 \mathrm{~m}^{2} \mathrm{~g}^{-1}$ with increasing reaction time $\left(0^{\circ} \mathrm{C}\right.$ for $4 \mathrm{~h}$ followed by $30^{\circ} \mathrm{C}$ for $8 \mathrm{~h}$ and $40^{\circ} \mathrm{C}$ for $12 \mathrm{~h}$, Fig 4b-4c) to finally $2385 \mathrm{~m}^{2} \mathrm{~g}^{-1}$ (gradual up-gradation of temperature from $0-80^{\circ} \mathrm{C}$ for $60 \mathrm{~h}$, Fig. $4 \mathrm{~d}-4 \mathrm{e}$ ). We observed a broad PSD in the mesoporous domain at the initial and intermediate stages of the solvent knitting process. The mesoporosity might originate from the inefficient packing of oligomers leading to the interparticle voids. However, the degree of crosslinking enhanced with the gradual increase in the reaction temperature and time, and eventually, the PSD profile was populated by the micropores centered at 0.64 and $0.89 \mathrm{~nm}$. The cyclic oligomeric cores consisting of two and three triptycene units connected through methylene bridges could be responsible for the generation of pores, respectively of 0.64 and $0.89 \mathrm{~nm}$ diameter. Such oligomeric cores were identified in the MALDITOF analysis of the reaction mixture after $30 \mathrm{~min}$ of the solvent knitting polymerization (Fig. 5a).

We further performed a series of control experiments to investigate the factors governing the morphology of SKTP. The Lewis-acid catalysts, their stoichiometry, solvents, and the reaction temperature were varied. Solvent knitting was carried out in the presence of both $\mathrm{FeCl}_{3}$ and $\mathrm{AlCl}_{3}$, resulting in similar types of 2D-sheet-like morphology. Whereas, no product was obtained using $\mathrm{SnCl}_{2}$ because of lower catalytic activity. The morphology of the solvent-knitted polymer was also altered by 


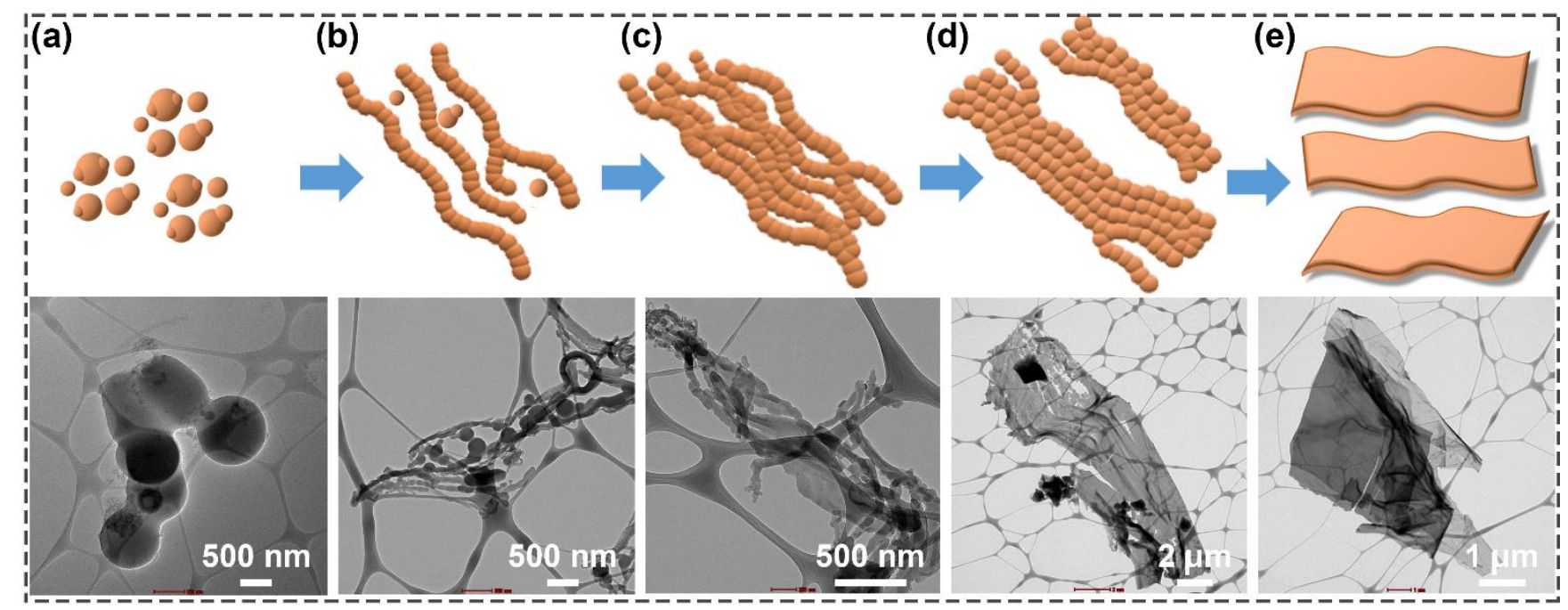

Fig. 4 Pictorial representation of morphological evolution of SKTP from nanosphere to nanoribbon followed by the lateral aggregation of nanoribbons to the 2D-nanosheet (a-e). Corresponding TEM images of materials acquired at different stages of solvent knitting process: (a) sphere formation, followed by (b) assembled spheres, resulting in (c) nanoribbons, followed by (d) assembling and crosslinking of nanoribbons leading to the (e) nanosheet formation.

the variation of the reaction medium. When chloroform was used as the solvent instead of DCM, the nanosheet formation was not observed. The above observation could be due to the tetrahedral geometry of $\mathrm{CHCl}_{3}$ having three propagating sites leading to a 3D network structure. On the other hand, we obtained truncated sheet-like morphology using a longer aliphatic chain containing solvent, 1,8-dibromooctane. The long flexible aliphatic crosslinkers prevented the $\pi-\pi$ stacking among the aromatic building units, and the random orientation of the linkers led to irregular truncated sheets. The non-uniform morphology with the coexistence of fused spheres and nanosheets was observed when the solvent knitting was carried out in DCM at a constant temperature $\left(80^{\circ} \mathrm{C}\right)$ for $60 \mathrm{~h}$. The constant heating at a temperature more than the boiling point of DCM led to rapid crosslinking of the triptycene units. Whereas, polymerization at $0^{\circ} \mathrm{C}$ for $60 \mathrm{~h}$ led to only spherical particles due to the lack of crosslinking. The results indicate that the gradual increase of the temperature for a fixed time interval has a profound impact on the self-assembly process of the polymer chains, leading to uniform sheet-like morphology of SKTP in the solvent knitting method.

The computational modelling was carried out to get an insight into the morphological evolution of SKTP thin sheets. The molecular structures of the oligomers identified through the MALDI-TOF analysis of the reaction mixture after $30 \mathrm{~min}$ of the solvent knitting polymerization were considered as the model repeating units (Fig. 5a). We observed the molecular ion peaks corresponding to the cyclic oligomers containing two [( $\left.\mathrm{C}_{42} \mathrm{H}_{26}\right)^{2+} ; \mathrm{m} / \mathrm{z}$ : calculated: 530.67, observed: 530.42$]$ and three triptycene moieties $\left[\left(\mathrm{C}_{65} \mathrm{H}_{44}\right)^{+} \mathrm{AlCl}_{4}{ }^{-} ; \mathrm{m} / \mathrm{z}\right.$ : calculated: 994.85, observed: 994.39] connected via methylene bridges (Fig. 5a). We also traced the linear and branched oligomers $\left[\left(\mathrm{C}_{88} \mathrm{H}_{61} \mathrm{Cl}_{3}\right)^{2+}\right.$; m/z: calculated: 1225.44, observed: 1224.80, Fig. 5a]. The MALDI-TOF analysis of the reaction mixture at the initial stages of the solvent knitting polymerization and HRTEM images of SKTP polymer at different time intervals provide a basis for the computational modelling.
Geometry optimization and energy minimization for the model structures were carried out using the Forcite module in Materials Studio 6.1. The optimized low energy conformation of the linear oligomers was employed for the molecular dynamics (MD) simulation in the microcanonical ensemble (NVE) using the Forcite module. The MD simulation resulted in a puckered conformation of linear oligomer with minimum conformational energy (Fig. 5b). The results supported the formation of nanospheres at the initial stage of the polycondensation. The oligomeric chains were subsequently crosslinked to nanoribbons upon the gradual increase of the polycondensation temperature (Fig. 5b). Further, the nanoribbons were crosslinked via methylene bridges resulting in nanosheets. The simulated structure of crosslinked triptycene chains revealed the 2D-sheet like topology with intrinsic pores $(0.6$ and $0.9 \mathrm{~nm})$ and voids generated due to interchain crosslinking (1.4 - $2 \mathrm{~nm})$ corroborated with the micropore analysis using nitrogen and ultramicropore analysis of carbon dioxide adsorption isotherms (Fig. 5b, Fig. 2d). The nanoribbons and subsequently nanosheet formation during the gradual increase of temperature in the solvent knitting process was confirmed through HRTEM analysis (Fig. 4).

\section{Organic micropollutant removal study}

The contrasting textural features of HCPs with the high specific surface area provided us the platform to explore the morphology-dependent sorption properties. Thus, we opted to address the removal of toxic micropollutants from water, a critical environmental concern at present. ${ }^{19,20} \mathrm{We}$ found the excellent adsorption capacity of SKTP $\left(1 \mathrm{mg} \mathrm{mL} \mathrm{mL}^{-1}\right)$ towards cationic methylene blue (MEB, $0.1 \mathrm{mM}$ ) with a percentage removal efficiency of $97 \pm 0.1 \%$ in 2 minutes compared to $27 \pm$ $2.7 \%$ and $30 \pm 3.2 \%$ exhibited by SCTP and FCTP, respectively (Fig. 6a). SKTP also showed much better performance for the removal of anionic micropollutant like rose bengal (RB, $0.1 \mathrm{mM}$, $81 \pm 2.5 \%, 2 \mathrm{~min}$ ) and neutral microplastic component bisphenol A (BPA, $0.1 \mathrm{mM}, 81 \pm 3.9 \%, 2 \mathrm{~min}$ ) than that of the other pristine HCPs (Fig. 6a). However, the adsorption efficiency was 

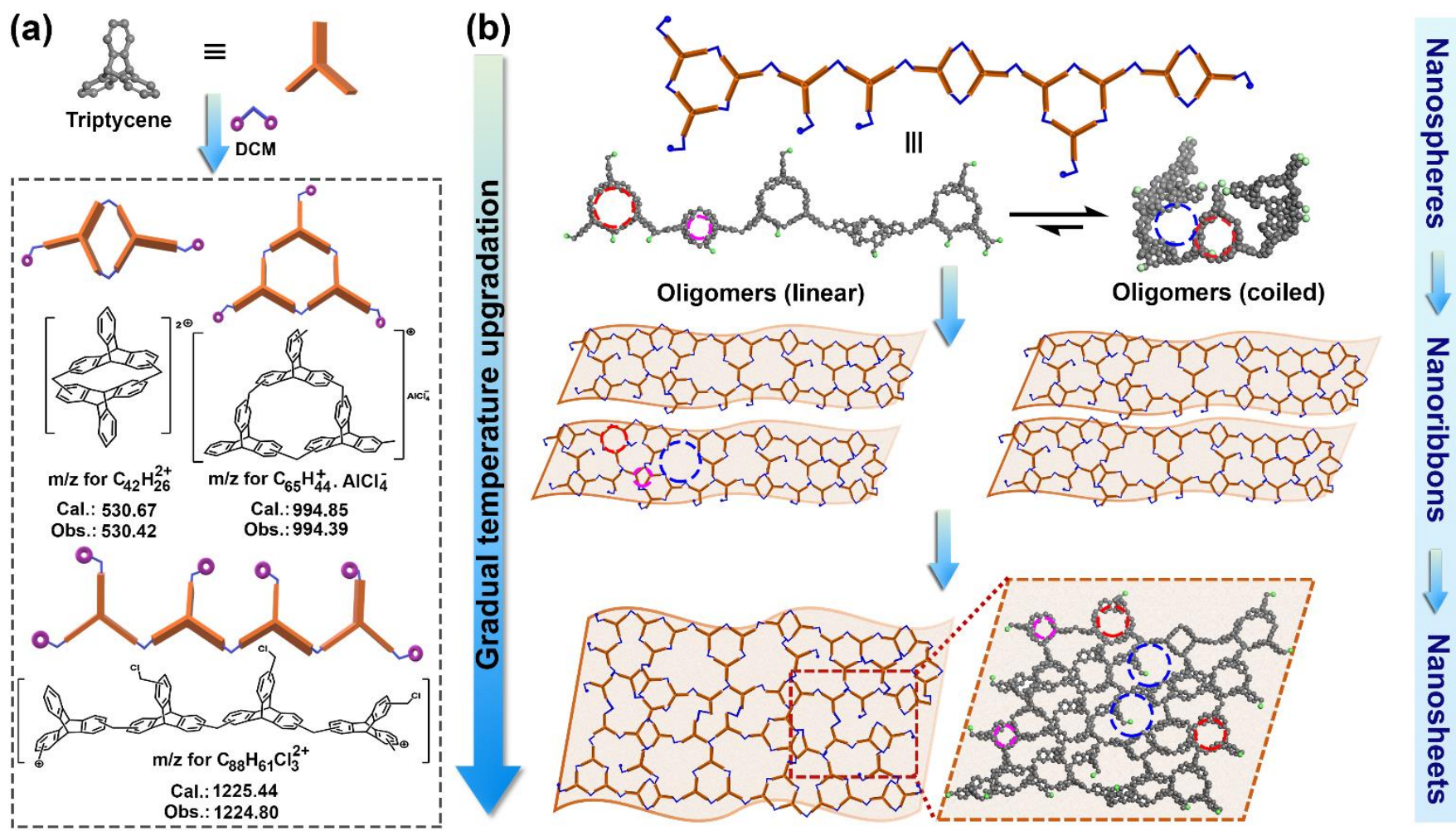

Fig. 5 (a) MALDI-TOF analysis of the samples obtained after $30 \mathrm{~min}$ of solvent knitting polymerization, suggesting the formation of cyclic and linear oligomers (ionic and neutra species). (b) Schematic illustration for the plausible step-wise self-assembly pathways leading to sheet-like morphology of SKTP polymer during solvent knitting polymerization. The structure of oligomers, nanoribbons, to nanosheets, are modelled computationally using the Forcite module in Material Studio 6.1. Geometry optimized structure of oligomers and nanosheets are represented by the space-filling model (grey: carbon, green: unreacted chlorine; H atoms excluded for better clarity). Pores of different dimensions (connecting two or three triptycene units through methylene bridges) are shown by dotted circles; magenta: pores by knitting two triptycene units; red: pores by knitting three triptycene units; blue: bigger pores originated from interchain crosslinking.

improved further with post-synthetic sulfonation due to the facile interactions between the $-\mathrm{SO}_{3} \mathrm{H}$ group of sulfonated polymers and heteroatoms present in the micropollutants. ${ }^{12 \mathrm{~b}}$ Sulfonated solvent knitting polymer, SKTPS $\left(1 \mathrm{mg} \mathrm{mL}^{-1}\right)$ exhibited superior separation efficiency (MEB: $100 \%$ in $0.5 \mathrm{~min}$; RB: $98 \pm 0.2 \%$ in $1 \mathrm{~min}$; BPA: $82 \pm 6.9 \%$ in $2 \mathrm{~min}$ ) than SCTPS (MEB: $88 \pm 4.1 \%$; RB: $85 \pm 0.2 \%$; BPA: $62 \pm 12.4 \%$ in $2 \mathrm{~min}$ ) and FCTPS (MEB: $66 \pm 2.2$; RB: $85 \pm 0.1 \%$; BPA: $65 \pm 7.2 \%$ in $2 \mathrm{~min}$ ), following the same trend as that of pristine HCPs (Fig. 6b). Further, the micropollutant removal study in a broad $\mathrm{pH}$ range (from 3 to 9) revealed the $\mathrm{pH}$-independent performance of SKTP and SKTPS, suggesting their practical relevance in water purification (Fig. $6 c)$.

We evaluated the ability of SKTPS $\left(1 \mathrm{mg} \mathrm{mL}^{-1}\right)$ for the removal of micropollutants of different sizes, functionality, and solubility. We used $0.1 \mathrm{mM}$ stock solution of respective micropollutants like pharmaceuticals, propranolol (PPN, a betablocker for the treatment of hypertension, $93 \pm 0.1 \%$ ),

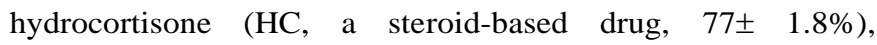
tetracycline (TC, an antibiotic, $72 \pm 2.4 \%$ ), plastic components like bisphenol A (BPA, $87 \pm 5.2 \%$ ), bisphenol S (BPS, $61 \pm$ $12 \%)$, organic dyes, like methylene blue $(100 \%)$, rose bengal $(98 \pm 0.1 \%)$, herbicide like paraquat (PQ, $93 \pm 3 \%)$, naphthyl or phenolic compounds, like 1-naphthyl amine (NA, $80 \pm 0.8 \%$ ), $\beta$ naphthol (NT, $97 \pm 2.3 \%$ ), 4-nitrophenol (NP, $92 \pm 2.7 \%$ ) which were efficiently separated from water within 5 min (Fig. 6d, 6e). SKTPS could effectively remove the micropollutants $(\sim 100 \%$ MEB, $100 \%$ RB, 95\% BPA) at environmentally relevant concentration $(10 \mu \mathrm{M})$ within $30 \mathrm{~S}$. SKTPS having abundant pores in between 0.6 to $1.5 \mathrm{~nm}$ preferentially sequestered cationic, anionic as well as neutral micropollutants with similar molecular dimensions (MEB: $1.55 \times 0.73 \mathrm{~nm}$; RB: $1.31 \times 1.33$ $\mathrm{nm}$; BPA: $1.03 \times 0.64 \mathrm{~nm}$, dimensions along $\mathrm{X}$ and $\mathrm{Y}$ direction, respectively) in equal ease from their equimolar mixture (Fig. 6f). On the other hand, the micropollutant with a larger molecular size, such as methyl blue (MB, $2.41 \mathrm{~nm} \times 1.76 \mathrm{~nm})$ was adsorbed at a significantly lower rate than a smaller one having a similar charge, like Rose Bengal. The results suggested the sizeselective micropollutant separation ability of SKTPS (Fig. 6g). Additionally, SKTPS was found to be highly recyclable without any loss in activity up to the $10^{\text {th }}$ cycle (Fig. 6h). The regeneration could easily be carried out by washing the polymer with ethanol and drying it under a vacuum.

The adsorption kinetics for MEB were fitted with Ho and McKay's pseudo-second-order model (correlation coefficient, $\left.\mathrm{R}^{2}>0.99\right) .{ }^{21}$ The pseudo-second-order rate constants $\left(k_{2}\right)$ for MEB, RB, and BPA adsorption by SKTPS were estimated to be 17.6, 2.1, and $0.3 \mathrm{~g} \mathrm{mg}^{-1} \mathrm{~min}^{-1}$, respectively. ${ }^{22}$ The rate constants for BPA removal by SKTPS are significantly higher compared to the commercially used carbonaceous adsorbents like Brita AC $\left(8.8 \times 10^{-3} \mathrm{mg}^{-1} \mathrm{~min}^{-1}\right), \mathrm{NAC}\left(9 \times 10^{-2} \mathrm{mg}^{-1} \mathrm{~min}^{-1}\right)$, GAC $(4.7 \times$ $\left.10^{-2} \mathrm{mg}^{-1} \mathrm{~min}^{-1}\right) .^{22}$ Additionally, the rate constant for the removal of cationic MEB by SKTPS (17.6 $\mathrm{mg}^{-1} \mathrm{~min}^{-1}$ ) is one of the highest among the best-known porous organic materials reported in the literature like covalent organic framework, e.g., TpPA-2 foam $\left(11.8 \mathrm{mg}^{-1} \mathrm{~min}^{-1}\right),{ }^{23}$ cavitand-based porous organic 

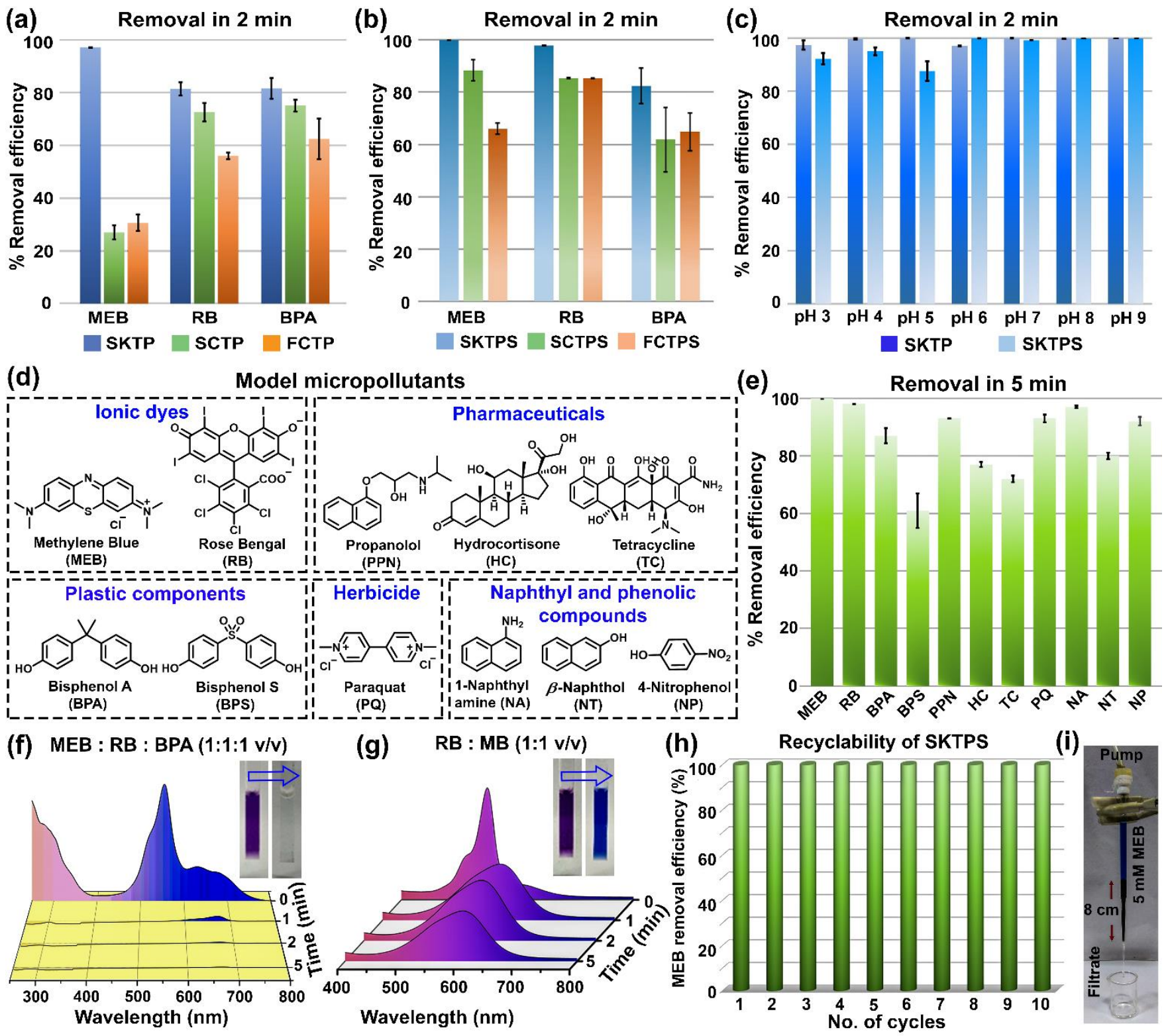

Fig. 6. Methylene Blue (MEB), Bisphenol A (BPA), Rose Bengal (RB) are chosen as model cationic, neutral, and anionic micropollutants to elucidate the morphological influence of nanoporous polymers in micropollutant removal. Comparison of micropollutant removal efficiency among (a) SKTP, SCTP, and FCTP, (b) sulfonated counterparts, SKTPS, SCTPS and FCTPS, (c) pH-dependent MEB removal using SKTP and SKTPS (micropollutant solution: $0.1 \mathrm{mM}$ and HCP dispersion: $1 \mathrm{mg} \mathrm{mL}^{-1}$ ). (d) Chemical structures of persistent organic micropollutants, including representative ionic dyes, pharmaceuticals, microplastic components, herbicide, naphthyl, and phenolic compounds. (e) Adsorption performance of SKTPS $\left(1 \mathrm{mg} \mathrm{mL}^{-1}\right)$ using a library of micropollutants $(0.1 \mathrm{mM})$. UV-Vis spectra suggesting the efficient removal of micropollutants having (f) similar molecular dimensions with different charges (cationic MEB, anionic RB, and neutral BPA) and $(\mathrm{g})$ different molecular dimensions with the same charges [anionic RB $(1.31 \times 1.33 \mathrm{~nm})$ and methyl blue, MB $(2.41 \times 1.76$ $\mathrm{nm})$ ] by SKTPS. (h) Recyclability of SKTPS $\left(1 \mathrm{mg} \mathrm{mL}^{-1}\right)$ for MEB $(0.05 \mathrm{mM})$ adsorption over 10 cycles. (i) Use of SKTPS as a column material for the filtration of dye-contaminated water (5 $\mathrm{mM}$ of MEB, column length: $8 \mathrm{~cm}$ and width: $0.5 \mathrm{~cm}$ ).

polymers, e.g., P5-P $\left(7.6 \times 10^{-2} \mathrm{mg}^{-1} \mathrm{~min}^{-1}\right),{ }^{24} \mathrm{P} 2\left(2.4 \times 10^{-2} \mathrm{mg}^{-}\right.$ $\left.{ }^{1} \mathrm{~min}^{-1}\right),{ }^{25}$ and hypercrosslinked polymer, e.g., AHCP-1 $(9.6 \times$ $\left.10^{-4} \mathrm{mg}^{-1} \mathrm{~min}^{-1}\right){ }^{26}$

The diffusion mechanism of micropollutants from solution to the pores of HCPs was rationalized through the fitting of the adsorption kinetics of MEB employing Weber's intra-particle diffusion model. ${ }^{27}$ According to this model, the adsorption process of analytes from the solution to the pores of HCPs consists of three consecutive steps, such as (a) liquid phase mass transport (external diffusion), followed by (b) pore diffusion (intra-particle diffusion), and finally (c) adsorption of analytes on the pore surface. For all the sulfonated HCPs, the data were fitted by two straight lines attributing the transfer of micropollutants from the solution to the polymer surface followed by the intra-particle diffusion through the pores of HCPs. ${ }^{27}$

The thermodynamics of dye adsorption of all the sulfonated polymers were fitted well (correlation coefficient, $R^{2}>0.9$ ) with the Langmuir model. The analysis suggested that the adsorption occurred at specific, energetically equivalent sites of the sulfonated HCPs with monolayer coverage of the micropollutant. ${ }^{27} \mathrm{We}$ found the maximum MEB adsorption capacity $\left(\mathrm{Q}_{\max }\right)$ of FCTPS, SCTPS, and SKTPS were 709, 285, and $374 \mathrm{mg} \mathrm{g}^{-1}$, respectively. The exceptional high uptake 

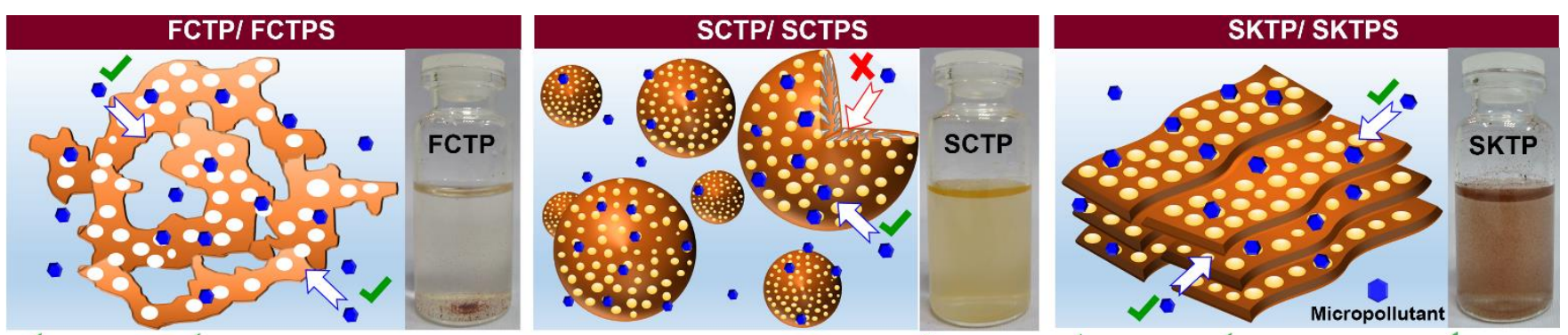

$\checkmark$ Broad PSD $\checkmark$ Pore accessability $\times$ Dispersity $\times$ Broad PSD $\times$ Pore accessability $\checkmark$ Dispersity $\checkmark$ Broad PSD $\checkmark$ Pore accessability $\checkmark$ Dispersity

Fig. 7 Proposed mechanism unfolding the morphological importance of micropollutant adsorption by nanoporous polymers with different morphologies; hierarchical pore size distribution (PSD), pore accessibility, and dispersity in water of layered sheet-like SKTP and SKTPS promote efficient adsorption.

capacity $(\mathrm{Q} \max )$ of FCTPS compared to the other sulfonated HCPs was due to the hierarchical PSD and greater $\%$ of external pore volume (pore diameter > $2 \mathrm{~nm}$; FCTPS: $53 \%$, SCTPS: $47 \%$, SKTPS: $34 \%{ }^{28}$ The Qmax values of SKTPS and FCTPS for MEB adsorption are comparable or higher than many benchmark porous materials reported in the literature like covalent organic framework, e.g., COF-based foam, e.g., TpBD foam (194 mg g $\left.{ }^{1}\right),{ }^{29}$ cavitand-based porous organic polymers, e.g., CalP (625 mg $\left.\mathrm{g}^{-1}\right),{ }^{30}$ hyper crosslinked polymer, e.g., THPS (330 $\left.\mathrm{mg} \mathrm{g}^{-1}\right),{ }^{31}$ conjugated microporous polymers, e.g., CMP-YA (1016 mg g$\left.{ }^{1}\right),{ }^{32}$ porous boron nitride nanosheets $\left(313 \mathrm{mg} \mathrm{g}^{-1}\right),{ }^{33}$ and $3 \mathrm{D}$ activated wood filter $\left(198.6 \mathrm{mg} \mathrm{g}^{-1}\right){ }^{34}$

We performed the filtration study by packing a column bed in a Pasture pipette using SKTPS polymer (column height: $8 \mathrm{~cm}$, width: $0.5 \mathrm{~cm})$. The filtration of deep blue MEB solution $(5 \mathrm{mM})$ resulted in a colorless filtrate ascertaining the promising scope of the sulphonated solvent knitting polymer for wastewater treatment (Fig. 6i). The micropollutant removal efficiency of the HCPs synthesized from solvent knitting is higher than that obtained through Friedel-Crafts reaction and Scholl coupling. The hierarchical pore size distribution due to irregular morphology with high specific surface area and pore volume (FCTP: 1.46 and FCTPS: $0.77 \mathrm{~cm}^{3} \mathrm{~g}^{-1}$ at $\mathrm{P} / \mathrm{P}_{0}$ 0.99) facilitate the uptake of micropollutants by the FC-mediated HCPs. But comparatively poor dispersity in aqueous medium (zeta potential, FCTP: $-0.5 \pm 0.3 \mathrm{mV}$ and FCTPS: $-9.1 \pm 2.2 \mathrm{mV}$ at $\mathrm{pH}$ $=7$ ) diminish the adsorption efficiency (Fig.7a). On the contrary, higher dispersity (zeta potential, SCTP: $-9.0 \pm 0.4 \mathrm{mV}$ and SCTPS: $-14.4 \pm 3.2 \mathrm{mV}$ at $\mathrm{pH}=7$ ) of SC-based HCPs enables better interactions among the micropollutants and the surface of the adsorbents (Fig. 7b). However, the unimodal pores at the ultramicropore domain $(<0.7 \mathrm{~nm})$ and the inaccessible deepseated pores due to the rigid sphere-like morphology impede the facile movement of analyte molecules. The excellent removal efficiency of SK-mediated HCPs is due to (i) high surface area (S BET: SKTP: $2385 \mathrm{~m}^{2} \mathrm{~g}^{-1}$ and SKTPS: $1444 \mathrm{~m}^{2} \mathrm{~g}^{-1}$ ) with high pore volume ( $\mathrm{V}_{\text {tot: }}$ SKTP: $1.34 \mathrm{~cm}^{3} \mathrm{~g}^{-1}$ and SKTPS: $0.88 \mathrm{~cm}^{3} \mathrm{~g}^{-1}$ at $\mathrm{P} / \mathrm{P}_{0} 0.99$ ), (ii) excellent dispersity (zeta potential, SKTP: $15.2 \pm 1.6 \mathrm{mV}$ and SKTPS: $-17.8 \pm 0.3 \mathrm{mV}$ at $\mathrm{pH}=7$ ) and (iii) accessible adsorption sites due to the $2 \mathrm{D}$-sheet-like structure enhancing interactions (electrostatic, $\pi-\pi$, and H-bonding) with water-soluble micropollutants (Fig. 7c). ${ }^{20 \mathrm{~b}}$ Therefore, the superiority of layered 2D-sheet-like morphology of HCPs over that of the irregular network and rigid sphere toward micropollutant removal from water is ascertained.

\section{Conclusions}

In summary, we investigated the origin of different morphologies of nanoporous HCPs synthesized through three standard synthetic techniques: Friedel-Crafts reaction, Scholl coupling, and solvent knitting. We explored the intriguing mechanistic details of the sheet-like morphology of SKTP polymer obtained through the solvent knitting method. The hierarchical self-assembly of nanospheres formed at the initial stages of solvent knitting polycondensation resulted in nanoribbons. Subsequently, the lateral aggregation of nanoribbons led to the formation of 2D-nanosheets. A comparative morphology-activity study based on the removal of persistent organic micropollutants was performed. We inferred that the highly porous and dispersible SKTP and its sulfonated counterpart, SKTPS having sheet-like morphology, showed the best performance over the spherical SCTP, SCTPS obtained from Scholl coupling and irregular particles of FCTP, FCTPS through Friedel-Crafts reaction. SKTPS exhibited a remarkable adsorption capacity ( $\mathrm{Q}_{\max }$ for MEB: $\left.374 \mathrm{mg} \mathrm{g}^{-1}\right)$, fast sorption kinetics (17.6 $\mathrm{g} \mathrm{mg}^{-1} \mathrm{~min}^{-1}$ ), wide working $\mathrm{pH}$ range ( $\mathrm{pH}$ : 3-9), and recyclability up to a minimum of 10 cycles without any decay in efficiency. Further exploration of solvent knitting polycondensation paves the way for the development of a new generation of low-cost, robust nanoporous adsorbent materials with well-defined 2D-sheet-like morphology for rapid sequestration of organic/inorganic micropollutants and desalination.

\section{Conflicts of interest}

There are no conflicts to declare.

\section{Acknowledgements}

Infrastructural support from IISERB, FIST supported TEM facility to the Dept. of Chemistry, IISERB, and the financial support from DST/CHM/2018/086 [DST/TM/WTI/WIC/2K17/82(G)] and SERB/CHM/2017/113 (file no. EMR/2017/000233) is gratefully acknowledged. AG, WH thank UGC, and SB thanks DST-Inspire for the fellowship. 


\section{Notes and references}

1 (a) Sakamoto, J.; van Heijst, J.; Lukin, O.; Schlüter, A. D. Angew. Chem. Int. Ed. 2009, 48, 1030; (b) Zhuang, X.; Gehrig, D.; Forler, N.; Liang, H.; Wagner, M.; Hansen, M. R.; Laquai, F.; Zhang, F.; Feng, X. Adv. Mater. 2015, 27, 3789.

2 (a) Liu, X.; Guan, C.; Wang, D.; Wan, L. Adv. Mater. 2014, 26, 6912; (b) Wang, K.; Huang, L.; Razzaque, S.; Jin, S.; Tan, B. small 2016, 12, 3134; (c) Gole, B.; Stepanenko, V.; Rager, S.; Grüne, M.; Medina, D. D.; Bein, T.; Würthner, F.; Beuerle, F. Angew. Chem. Int. Ed. 2018, 57, 846; (d) Chun, J.; Park, J. H.; Kim, J.; Lee, S. M.; Kim, H. J.; Son, S. U. Chem. Mater. 2019, 31, 300 .

3 (a) Thomas, A. Angew. Chem. Int. Ed. 2010, 49, 8328; (b) Furukawa, H.; Cordova, K. E.; O'Keeffe, M.; Yaghi, O. M. Science 2013, 341, 1230444J; (c) Patra A.; Scherf, U. Chem.Eur. J. 2012, 18, 10074; (d) Tan, L.; Tan, B. Chem. Soc. Rev., 2017, 46, 3322; (e) Huang, K.; Zhang, J. Y.; Liu F. J.; Dai, S. ACS Catal. 2018, 8, 9079; (f) Lee, M.; Cooper, A. I. Chem. Rev. 2020, 120, 2171; (g) Tian Y.; Zhu, G. Chem. Rev. 2020, 120, 8934; (h) Geng, K.; He, T.; Liu, R.; Tan, K. T.; Li, Z.; Tao, S.; Gong, Y.; Jiang, Q.; Jiang, D. Chem. Rev. 2020, 120, 8814.

4 Davankov, V. A.; Rogozhin S. V.; Tsyurupa, M. P. US. Pat. 3729457, 1971.

5 Trewin A.; Cooper, A. I. Angew. Chem. Int. Ed. 2010, 49, 1533.

6 (a) Zhang, H.; Noonan, O.; Huang, X.; Yang, Y.; Xu, C.; Zhou, L.; Yu, C. ACS Nano 2016, 10, 4579; (b) Jang, J. Y.; Le, T. M. D.; Ko, J. H.; Ko, Y.; Lee, S. M.; Kim, H. J.; Jeong, J. H.; Thambi, T.; Lee D. S.; Son, S. U. Chem. Mater. 2018, 31, 300; (c) Razzaque, S.; Cheng, Y.; Hussain I.; Tan, B. Polym. Chem. 2020, $11,2110$.

7 (a) Li, X.; Xiong, H.; Jia, Q. ACS Appl. Mater. Interfaces 2019, 11, 46205; (b) Song, W.; Zhang, Y.; Varyambath A.; Kim, I. ACS Nano 2019, 13, 11753.

8 Wang, S.; Zhang, C.; Shu, Y.; Jiang, S.; Xia, Q.; Chen, L.; Jin, S.; Hussain, I.; Cooper, A. I.; Tan, B. Sci. $A d v$. 2017, 3, e1602610.

9 Gao, T.; Wang, T.; Wu, W.; Liu, Y.; Huo, Q.; Qiao, Z.; Dai, S. Adv. Mater. 2019, 31, 1806254.

10 Wang, X. Y.; Mu, P.; Zhang, C.; Chen, Y.; Zeng, J. H.; Wang F.; Jiang, J. X. ACS Appl. Mater. Interfaces 2017, 9, 20779.

11 (a) Long, T. M.; Swager, T. M. Adv. Mater. 2001, 13, 601; (b) Corrado, T.; Guo, R. Mol. Syst. Des. Eng. 2020, 5, 22.

12 (a) Aken, K. V.; Strekowski L.; Patiny, L. Beilstein J. Org. Chem. 2006, 2, 3, DOI: 10.1186/1860-5397-2-3; (b) Charpe, V. P.; Sagadevan A.; Hwang, K. C. Green Chem. 2020, 22, 4426.

13 (a) Kang, D. W.; Kang, M.; Moon, M.; Kim, H.; Eom, S.; Choe, J. H.; Lee W. R.; Hong, C. S. Chem. Sci. 2018, 9, 6871. (b) Kang, H. G.; Lee, K. M.; Choi, S.; Nam, B.; Choi, S.; Lee, S. C.; Park, J. Y.; Lee, G. W.; Lee H. U.; Lee, Y. C. $R S C A d v$. 2015, 5, 63271.

14 Li, Z.; Yao, Y.; Wang, D.; Hasan, M. M.; Suwansoontorn, A.; Li, H.; Du, G.; Liu, Z.; Nagao, Y. Mater. Chem. Front. 2020, 4, 2339 .

15 Thommes, M.; Kaneko, K.; Neimark, A. V.; Olivier, J. P.; Rodriguez-Reinoso, F.; Rouquerol J.; Sing, K. S. W. Pure Appl. Chem. 2015, 87, 1051.

16 Landers, J.; Gor, G. Y.; Neimark, A. V. Colloids and Surfaces A: Physicochem. Eng. Aspects 2013, 437, 3.

17 Zhang, G. W.; Li, P. F.; Meng, Z.; Wang, H. X.; Han, Y.; Chen, C. F. Angew. Chem. Int. Ed. 2016, 55, 5304.

18 Hou, S.; Razzaque S.; Tan, B. Polym. Chem. 2019, 10, 1299.

19 Sackaria, M.; Elango, L. Water Environ. Res. 2019, DOI: 10.1002/wer.1243.
20 (a) Alimi, O. S.; Budarz, J. F.; Hernandez, L. M.; Tufenkji, N.; Environ. Sci. Technol. 2018, 52, 1704; (b) Rojas, S.; Horcajada, P., Chem. Rev. 2020, 120, 8378.

21 Ho, Y. S.; McKay, G. Process. Biochem. 1999, 34, 451.

22 Alsbaiee, A.; Smith, B. J.; Xiao, L.; Ling, Y.; Helbling, D. E.; Dichtel, W. R. Nature 2016, 529, 190.

23 Karak, S.; Dey, K.; Torris, A.; Halder, A.; Bera, S.; Kanheerampockil, F.; Banerjee, R. J. Am. Chem. Soc. 2019, 141,7572 .

24 Shi, B.; Guan, H.; Shangguan, L.; Wang, H.; Xia, D.; Kong, X.; Huang, F. J. Mater. Chem. A 2017, 5, 24217.

25 Wang, X.; Xie, L.; Lin, K.; Ma, W.; Zhao, T.; Ji, X.; Khashab, N. M.; Alyami, M.; Wang, H.; Sessler, J. L. Angew. Chem. Int. Ed. 2020, 60, 7188.

26 Shen, R.; Yan, X.; Guan, Y.; Zhu, W.; Li, T.; Liu, X.; Li, Y.; Gu, Z. Polym. Chem. 2018, 9, 4724.

27 Roy, A.; Adhikari, B.; Majumder, S. B. Ind. Eng. Chem. Res. 2013, 52, 6502

28 (a) Walker, G.M.; Weatherley, L.R. Chem. Eng. J. 2001, 83, 201; (b) Ip, A. W. M.; Barford, J. P.; McKay, G. J. Colloid Interface Sci. 2009, 337, 32.

29 Mohammed, A. K.; Usgaonkar, S.; Kanheerampockil, F.; Karak, S.; Halder, A.; Tharkar, M.; Addicoat, M.; Ajithkumar, T. G.; Banerjee, R. J. Am. Chem. Soc. 2020, 142, 8252.

30 Shetty, D.; Jahovic, I.; Raya, J.; Ravaux, F.; Jouiad, M.; Olsen, J.; Trabolsi, A. J. Mater. Chem. A 2017, 5, 62.

31 Zhang, C.; Zhu, P.; Tan, L.; Liu, J.; Tan, B.; Yang, X.; Xu, H.; Macromolecules 2015, 48, 8509.

32 Yuan, Y.; Huang, H.; Chen, L.; Chen, Y. Macromolecules 2017, 50, 4993.

33 Lei, W.; Portehault, D.; Liu, D.; Qin, S.; Chen, Y. Nat. Commun. 2013, 4, 1777.

34 Jiao, M.; Yao, Y.; Chen, C.; Jiang, B.; Pastel, G.; Lin, Z.; Wu, Q.; Cui, M.; He, S.; Hu, L. ACS Materials Lett. 2020, 2, 430. 